\title{
Dual effect of disopyramide on atrial and atrioventricular conduction and refractory periods
}

\author{
J. S. BIRKHEAD AND E. M. VAUGHAN WILLIAMS \\ From the Departments of Cardiology and Pharmacology, Oxford University
}

\begin{abstract}
Disopyramide has been shown in conditions of cholinergic blockade to have a depressant effect upon sinus node automaticity and the atrial refractoriness. It also prolongs atrioventricular conduction and increases atrioventricular refractoriness. These effects may often be masked in vivo by the anticholinergic effects of the drug.
\end{abstract}

Disopyramide ${ }^{1}$ is an antiarrhythmic compound which is effective against both ventricular and supraventricular arrhythmias (Jennings et al., 1976; Mizgala and Huvell, 1976) and may also be of value in tachyarrhythmias related to the WolffParkinson-White syndrome (Spurrell et al., 1975).

It has been shown in vitro to reduce the maximum rate of depolarisation in both atrial (Sekiya and Vaughan Williams, 1963) and ventricular tissues (Yeh et al., 1973) and is a local anaesthetic. It is thus an antiarrhythmic drug of the first class. In addition, it slightly prolongs the duration of the atrial action potential in vitro (Sekiya and Vaughan Williams, 1963) and in vivo (Edwards et al., 1976) (Class 3 action). A drug possessing membrane stabilising properties on atrial and ventricular tissue might be expected to prolong the functional refractory period. Though such an effect has been shown in the ventricles in man (Spurrell et al., 1975), there has been considerable disagreement concerning the action of this compound upon sinus node, atrial, and atrioventricular nodal function. It has been suggested that the variability of the electrophysiological responses of these tissues to the drug may be the result of an atropine-like action of disopyramide (Sekiya and Vaughan Williams, 1963) which would shorten atrial and atrioventricular nodal conduction time, especially if vagal tone was high, and thus mask the direct depressant effect of the compound.

The present study was undertaken to investigate the effect of intravenously administered disopyramide when the parasympathetic control of the heart had already been antagonised by atropine, in order to allow any direct depressant effect of the com-

'Rythmodan, Roussel.

Received for publication 1 November 1976 pound to become manifest. Thus the relative contribution of the two actions could be assessed.

\section{Patients and methods}

Fourteen patients were studied (Table 1). Twelve had clinical or electrocardiological evidence of arrhythmias and the primary investigation was the study of the arrhythmias. One had mild pulmonary stenosis, and underwent right heart catheterisation, and another patient had ischaemic heart disease. All gave informed and written consent to the further procedures described here. None was receiving any cardioactive or other medication, and all were studied in a fasting state.

A quadripolar pacing catheter (USCI $5 \mathrm{~F}$ ) was introduced percutaneously into the right femoral vein and advanced to the high right atrium under fluoroscopic control. The distal pair of electrodes was used to pace the high right atrium at the junction with the superior vena cava. The proximal pair of electrodes recorded a high right atrial electrogram. A second, bipolar, pacing electrode (USCI $5 \mathrm{~F} / 6 \mathrm{~F}$ ) was introduced percutaneously via the right femoral vein and advanced under fluoroscopic control through the tricuspid valve to a position suitable for recording the His bundle deflection. The intracardiac potentials were recorded, suitably filtered, together with three surface electrocardiographic leads (Standard leads I, II, III, or V1), using an Elema-Schonander Mingograph 82 at a paper speed of $100 \mathrm{~mm} \mathrm{~s}^{-1}$. Pacing and programmed stimuli, of $2 \mathrm{~ms}$ duration and twice threshold strength, were delivered by a speciallybuilt stimulator, based on the Grass S44 module.

The high right atrium was paced at rates of 110 , $130,150 \mathrm{~min}^{-1}(1 \cdot 8,2 \cdot 2$, and $2 \cdot 5 \mathrm{~Hz})$. Sinus node recovery time was measured as the time from the 
Table 1

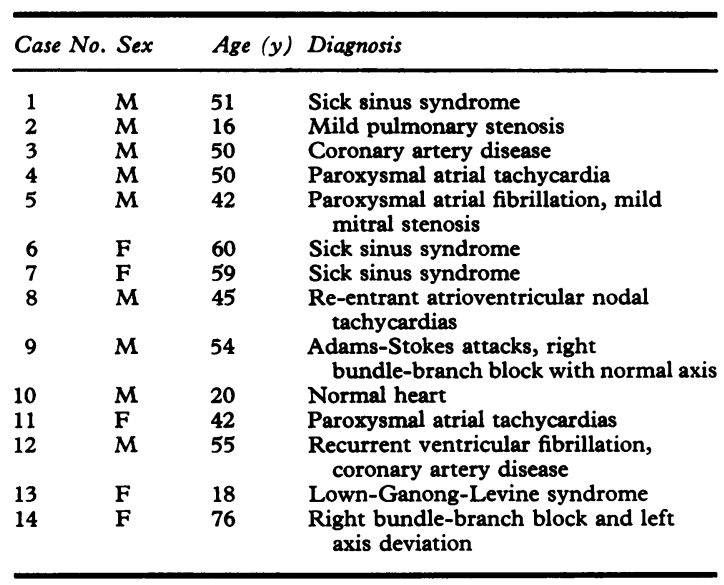

last stimulus of a 2 min train at $150 \mathrm{~min}^{-1}(2.5 \mathrm{~Hz})$ to the onset of the first spontaneous sinus impulse. The refractory periods of the atrium and atrioventricular node were determined during fixed rate pacing by the introduction of premature stimuli (St 2). The fixed driving rate employed was in the range 1.6 to $2.1 \mathrm{~Hz}$ (600 to $475 \mathrm{~ms} \mathrm{RR}$ intervals), and was constant for each patient. Heart rate, sinus node recovery time, atrial and atrioventricular conduction times, and the refractory periods of the atrium and atrioventricular node were measured under basal conditions, and after the intravenous injection of atropine sulphate, $0.025 \mathrm{mg} \mathrm{kg}^{-1}$. Measurements were then repeated after the intravenous injection (over $2 \mathrm{~min}$ ) of disopyramide $2 \mathrm{mg} \mathrm{kg}^{-1}$.

Measurements were completed within 15 minutes of the end of the injection, at which time plasma concentration would be expected to be within the therapeutic range (Ward and Kinghorn, 1976; Spurrell et al., 1975).

\section{Definitions}

R-R: the cycle length of the paced or spontaneous rhythm, in ms.

HRA-LRA: the time in ms from the origin of the high right atrial potential to the origin of the low right atrial potential seen on the His bundle electrogram, representing right atrial conduction time.

LRA-H: the time in ms from the low right atrial potential seen on the His bundle electrogram to the His potential, representing atrioventricular-nodal conduction time.

St1-St2: the time in $\mathrm{ms}$ between a pacing stimulus and a premature stimulus.

ERP atrium: the effective refractory period of the atrium is the longest St1-St2 interval that does not result in atrial depolarisation by St2.

ERP-AVN: the effective refractory period of the atrioventricular node is the longest LRA1-LRA2 interval that does not result in conduction of LRA2 to the bundle of His.

FRP-AVN: the functional refractory period of the atrioventricular node is the shortest $\mathrm{H} 1-\mathrm{H} 2$ interval resulting from two atrial depolarisations.

\section{Results}

These are summarised in Tables 2 and 3.

The mean sinus node recovery time was shortened by atropine from $947 \pm 321$ to $714 \pm 167 \mathrm{~ms}$ $(\mathrm{P}<0.01 ; \mathrm{n}=7)$, and the mean heart rate increasəd from $70 \pm 18$ to $105 \pm 27$ beats per $\min (P<0.001$; $\mathrm{n}=14)$. The mean ERP of the atrium was shortened from $258 \pm 31$ to $232 \pm 33$ (NS; $n=9$ ). The FRP of the atrioventricular node was shortened from $429 \pm 68$ to $355 \pm 38 \mathrm{~ms}(\mathbf{P}<0.01 ; n=9)$.

All the results reported in the following section refer to the effect of disopyramide $2 \mathrm{mg} \mathrm{kg}^{-1}$ in patients who had been pretreated with atropine $0.025 \mathrm{mg} \mathrm{kg}^{-1}$.

The mean sinus node recovery time was prolonged from $714 \pm 167$ to $826 \pm 223 \mathrm{~ms} \quad(P<0.01$; $\mathrm{n}=7$ ). The mean heart rate was reduced from $105 \pm 27$ to $87 \pm 23$ per $\min (P<0.001 ; n=14)$. The mean ERP of the atrium was increased from $232 \pm$ 33 to $268 \pm 43 \mathrm{~ms}(\mathrm{P}<0.01 ; \mathrm{n}=9)$. The LRA-H interval in sinus rhythm was prolonged from $80 \pm 15$ to $91 \pm 16 \mathrm{~ms}(\mathrm{P}<0.01 ; \mathrm{n}=14)$. With high right atrial pacing at $130 \mathrm{~min}^{-1}(2.2 \mathrm{~Hz})$ the prolongation was more pronounced, being from $78 \pm 33$ to $148 \pm 76 \mathrm{~ms}(P<0.05 ; n=7)$. The ERP of the atrioventricular node could only be measured on 2 out of 9 occasions in 7 patients when this was longer than the ERP of the atrium. The FRP of the atrioventricular node was much increased from $355 \pm 38$ to $423 \pm 54 \mathrm{~ms}(\mathrm{P}<0.001 ; \mathrm{n}=9)$. There were small and insignificant changes in intra-atrial and HisPurkinje conduction times.

Table 2 Values for heart rate, sinus node recovery time, and intracardiac conduction time

\begin{tabular}{lccccc}
\hline & Basal & $\begin{array}{c}\text { Atropine } \\
(0.025 \mathrm{mg} / \mathrm{kg})\end{array}$ & $\begin{array}{l}\text { Disopyramide } \\
(2 \mathrm{mg} / \mathrm{kg})\end{array}$ & \\
\hline Heart rate & $70 \pm 18 \mathrm{~min}$ & $105 \pm 27$ & $87 \pm 23$ & $\mathrm{n}=14$ \\
Sinus node & & & & \\
$\quad$ recovery time & $947 \pm 32 \mathrm{~ms}$ & $714 \pm 167$ & $826 \pm 223$ & $\mathrm{n}=7$ \\
HRA-LRA & $39 \pm 12 \mathrm{~ms}$ & $36 \pm 8$ & $39 \pm 9$ & $\mathbf{n}=8$ \\
LRA-H & $92 \pm 20 \mathrm{~ms}$ & $80 \pm 15$ & $91 \pm 16$ & $\mathrm{n}=14$ \\
& $123 \pm 34 \mathrm{~ms}$ & $87 \pm 23^{\star}$ & $120 \pm 43^{\star}$ & $\mathbf{n}=7$ \\
HV & $137 \pm 36 \dagger \mathrm{ms}$ & $78 \pm 33 \dagger$ & $148 \pm 78 \dagger$ & $\mathrm{n}=7$ \\
& $49 \pm 7 \mathrm{~ms}$ & $47 \pm 9$ & $50 \pm 8$ & $\mathrm{n}=14$ \\
\hline
\end{tabular}

^During high right atrial pacing at $110 \mathrm{~min}^{-1}$. tDuring high right atrial pacing at $130 \mathrm{~min}^{-1}$. 
Table 3 Effective refractory period of atrium and functional refractory period of atrioventricular node measured in milliseconds

\begin{tabular}{|c|c|c|c|c|c|c|c|}
\hline Case No. & Driving rate & $\begin{array}{l}\text { ERP of atrium } \\
\text { Basal }\end{array}$ & $\begin{array}{l}\text { (ms) } \\
\text { Atropine }\end{array}$ & Disopyramide & $\begin{array}{l}\text { FRP of } \\
\text { Basal }\end{array}$ & $\begin{array}{l}\text { (ms) } \\
\text { Atropine }\end{array}$ & Disopyramide \\
\hline $\begin{array}{l}1 \\
2 \\
3 \\
4 \\
5 \\
6 \\
7 \\
8^{*}\end{array}$ & $\begin{array}{l}600 \\
475 \\
475 \\
500 \\
500 \\
500 \\
600 \\
550 \\
500 \\
430\end{array}$ & $\begin{array}{l}330 \\
275 \\
230 \\
275 \\
230 \\
250 \\
240 \\
255 \\
240 \\
230\end{array}$ & $\begin{array}{l}205 \\
165 \\
250 \\
225 \\
255 \\
285 \\
225 \\
240 \\
240 \\
240\end{array}$ & $\begin{array}{l}220 \\
210 \\
210 \\
300 \\
290 \\
325 \\
270 \\
290 \\
300 \\
255\end{array}$ & $\begin{array}{l}550 \\
375 \\
375 \\
470 \\
415 \\
510 \\
435 \\
385 \\
350 \\
415\end{array}$ & $\begin{array}{l}400 \\
335 \\
290 \\
415 \\
370 \\
345 \\
375 \\
340 \\
330 \\
370\end{array}$ & $\begin{array}{l}450 \\
350 \\
330 \\
470 \\
415 \\
445 \\
500 \\
440 \\
410 \\
455\end{array}$ \\
\hline \multicolumn{2}{|c|}{ Mean and SEM } & $258 \pm 31$ & $\begin{array}{l}232 \pm 33 \\
\text { NS }\end{array}$ & $\begin{array}{l}268 \pm 43 \\
P<0.01\end{array}$ & $429 \pm 68$ & $\begin{array}{l}355 \pm 38 \\
P<0.01\end{array}$ & $\begin{array}{l}423 \pm 54 \\
P<0.001\end{array}$ \\
\hline
\end{tabular}

- Case 8 was studied at three driving rates

\section{Discussion}

Intracellular studies on isolated rabbit atria (Sekiya and Vaughan Williams, 1963) and isolated ventricular fibres (Yeh et al., 1973) of the effect of disopyramide have shown 'membrane stabilising' properties indicating that the drug is an antiarrhythmic agent of the first class (Vaughan Williams, 1975). It is also a local anaesthetic. Sekiya and Vaughan Williams (1963) also showed a prolongation of action potential duration (class 3 action), during intracellular recording on rabbit atria, which has been confirmed in the anaesthetised dog by Edwards et al. (1976) recording monophasic action potentials with suction electrodes. The expected findings in man with a compound having the above properties would be a prolongation of atrial, atrioventricular nodal, and ventricular refractoriness. While Spurrell et al. (1975) have shown a clear-cut prolongation in the refractory period of the ventricle, there has been considerable variation in the reported effects of disopyramide upon sinus node automaticity, atrial and atrioventricular conduction times, and refractory periods.

Befeler et al. (1975) have shown a modest reduction in sinus node recovery time 15 minutes after administration, but which later increased to $146 \mathrm{~ms}$ 30 minutes after administration. If this reduction in sinus node recovery time had been the result of the anticholinergic properties of disopyramide then it might have been expected that the sinus rate would also have increased, but the authors state that the basic sinus rate was not altered. In the present study a fall in heart rate has been noted together with a prolongation of the sinus node recovery time, results which are both in accord with in vitro studies.

Spurrell et al. (1975) found that the disopyramide produced pronounced prolongation in the effective refractory period of the atrium in 7 patients. On the other hand, Josephson et al. (1973) did not see consistent changes; in 24 measurements in 12 patients the atrial effective refractory period was prolonged in 13 , shortened in 6 , and unchanged in 5 . There was a small mean prolongation of $13 \mathrm{~ms}$. Similarly, Befeler et al. (1975) did not observe consistent changes, but noted a small mean shortening of the atrial effective refractory period of $30 \mathrm{~ms}$. The present study showed a mean prolongation of atrial effective refractory period from $232 \pm 33$ to $268 \pm$ $43 \mathrm{~ms}$.

All these apparently conflicting results may be reconciled. After cholinergic blockade with atropine the prolongation of atrial effective refractory period shown in this study is in agreement with the depressant action on conduction reported in studies in vitro. It is apparent that in vivo the total effect of disopyramide depends upon the degree of vagal tone. If this is high then the anticholinergic action of disopyramide predominates, and the resultant effect is a shortening of the atrial effective refractory period. When vagal action is abolished by atropine then the direct depressant action of disopyramide is shown and a lengthening of atrial effective refractory period is observed.

Variable effects of disopyramide have also been reported on atrioventricular conduction and refractory periods. Josephson et al. (1973) found disopyramide shortened the effective refractory period of the atrioventricular node and was without effect on the functional refractory period. Marrott et al. (1975) did not find any consistent alteration in the effective refractory period of the atrioventricular node. Befeler et al. (1975) also found the effective refractory period of the atrioventricular node to be unchanged after disopyramide but showed a small 
increase in the functional refractory period of the atrioventricular node. In the present work, after cholinergic blockade, disopyramide produced a consistent and pronounced prolongation in the functional refractory period of the atrioventricular node of $68 \pm 34 \mathrm{~ms}$. There was also a prolongation of the resting LRA-H interval of $11 \pm 5 \mathrm{~ms}$, and this prolongation became even more pronounced during high right atrial pacing.

These results suggest that, after cholinergic blockade, disopyramide exerts purely depressant effects upon the sinus node, atrium, and atrioventricular node. It is suggested that the variable results previously shown can be explained by the interaction of the blockade of intrinsic vagal tone and the direct depressant effect of disopyramide.

The question arises, if this interpretation is accepted, whether it could provide a rational basis for the selection of the types of arrhythmia where disopyramide might be appropriate. From the present study it appears that disopyramide should be effective in areas where there is no parasympathetic innervation, such as the His-Purkinje system, ventricular myocardium, and the accessory pathways found in pre-excitation syndromes. This conclusion is in agreement with the empirical clinical findings of several workers.

The anticholinergic effect may also be of value in arrhythmia prophylaxis after myocardial infarction when atrioventricular conduction delay may be a problem (Jennings et al., 1976).

A proviso should be made on the above conclusions. This study observed the effects of disopyramide during the first 15 minutes after administration. No published human work has assessed the effect of disopyramide upon the conduction system for longer than 30 minutes. Edwards et al. (1976) have shown in anaesthetised dogs that monophasic action potentials (a measure of the intracellular action potential) recorded with suction electrodes did not achieve maximum prolongation after disopyramide until 30 to 45 minutes after administration. This suggests that previous human studies may have mainly related to the effects of class 1 actions of diosopyramide and that the class 3 actions, if of slower onset, may have been underestimated. Amiodarone, a compound having predominantly class 3 actions, has significant antiarrhythmic actions against atrial arrhythmias (Olsson et al., 1973), and thus the class 3 actions possessed by disopyramide may be of similar importance.

Although the present study may explain the inconsistencies noted between previous reports on the basis of the dual action of disopyramide the full electrophysiological effect of disopyramide in- cluding the class 3 actions has not yet been fully elucidated.

The authors acknowledge the financial assistance of Roussel Ltd., who also provided supplies of disopyramide.

\section{References}

Befeler, B., Castellanos, A., Wells, D. E., Vagueiro, M. C., and Yeh, B. K. (1975). Electrophysiologic effects of the antiarrhythmic agent disopyramide phosphate. American fournal of Cardiology, 35, 282-287.

Edwards, I. R., Martin, J. F., and Ward, J. W. (1976). The effect of disopyramide on in vivo measurement of monophasic action potential in canine heart muscle. Fournal of International Medical Research, 4, Suppl. 1, 26-30.

Jennings, G., Jones, M. B. S., Besterman, E. M. M., Model, D. G., Turner, P. P., and Kidner, P. H. (1976). Oral disopyramide in prophylaxis of arrhythmias following myocardial infarction. Lancet, 1, 51-54.

Josephson, M. E., Caracta, A. R., Lau, S. L., Gallagher, J. J., and Damato, R. N. (1973). Electrophysiological evaluation of disopyramide in man. American Heart fournal, 86, 771780.

Marrott, P. K., Ruttley, M. S. T., Winterbottam, J. T., and Muir, J. R. (1975). Disopyramide: a study of its acute electrophysiological and haemodynamic effects. British Fournal of Clinical Pharmacology, 2, 373 P.

Mizgala, H. F., and Huvelle, P. R. (1976). Acute termination of cardiac arrhythmias with intravenous disopyramide. fournal of International Medical Research, 4, Suppl. 1, 82-85.

Olsson, S. B., Brorson, L., and Varnauskas, E. (1973). Class 3 antiarrhythmic action in man. Observations from monophasic action potential recordings and amiodarone treatment. British Heart fournal, 35, 1255-1259.

Sekiya, A., and Vaughan Williams, E. M. (1963). A comparison of the antifibrillatory actions and effects on intracellular cardiac potentials of pronethalol, disopyramide and Quinidine. British Fournal of Pharmacology and Chemotherapy, 21, 473-481.

Spurrell, R. A. J., Thorburn, C. W., Camm, J., Sowton, E., and Deuchar, D. C. (1975). Effects of disopyramide on electrophysiological properties of specialized conduction system in man and on accessory atrioventricular pathway in Wolff-Parkinson-White syndrome. British Heart Fournal, 37, 861-867.

Vaughan Williams, E. M. (1975). Classification of antiarrhythmic drugs. Pharmacology and Therapeutics B, 1, 115-138.

Ward, J. W., and Kinghorn, G. R. (1976). The pharmacokinetics of disopyramide following myocardial infarction with special reference to oral and intravenous dose regimes. Fournal of International Medical Research, 4, Suppl. 1, 4953.

Yeh, B. K., Sung, P., and Scherlag, B. J. (1973). Effects of disopyramide on electrophysiological and mechanical properties of the heart. Fournal of Pharmaceutical Sciences, 62, 1924-1929.

Requests for reprints to Dr. J. S. Birkhead, General Hospital, Northampton NN1 4QR. 